\title{
25-km long transmission and real-time detection of 5-GBd/s optical QPSK data using external phase-error compensation
}

\author{
Trong-Thuy Ha, Yong-Yuk Won and Dongsun Seo \\ Department of Electronics, Myongji University, Yongin, Gyonggido 17058, Korea \\ sdsphoto@mju.ac.kr
}

Received: 05.02 .2021

\begin{abstract}
We suggest a simple new method for tracking and compensating phase errors. It enables detecting directly optical quadrature-phase shift-keying (QPSK) data after their transmission over more than $10 \mathrm{~km}$, which is far beyond the coherent lengths of typical laser sources. The phase error is extracted by taking the power difference between the in-phase and quadrature-phase signals of the random QPSK data. This error is compensated by simply applying the error signal to a phase modulator located in front of a local oscillator for coherent detection. This direct phase-error compensation enables real-time detection of the QPSK data with no digital signal-processing techniques. As an experimental proof, we demonstrate for the first time a successful transmission of $5 \mathrm{GBd} / \mathrm{s}$ QPSK data through a $25-\mathrm{km}$ long standard single-mode fibre. We also show that our phase-error compensation idea can be extended to transmission of wavelength-division multiplexed QPSK data.
\end{abstract}

Keywords: coherent optical communications, phase-error compensation, quadrature-phase shift keying, optical phase-locked loop

UDC: $535.41+621.391$

\section{Introduction}

Coherent detection [1] of multi-level amplitude- and phase-modulated optical signals provides high spectral efficiency and aids in implementing cost-effective optical transmission systems. To satisfy enormous traffic demands, a coherent system can be combined with a wavelength-division multiplexing (WDM) technique to maximize optical transmission capacity [2]. However, one of the most severe impairments that affect the coherent systems employing high-order phase and amplitude modulation formats is a presence of phase noise [3, 4], which can be introduced by a transmitter, a receiver (i.e., a local oscillator) or some other devices. Large phase noises of laser sources prevent correct detection of transmitted data and degrade significantly the performance of the coherent systems.

Fortunately, external-cavity laser diodes of compact sizes have been developed and are now commercially available. However, their linewidth approaching several hundred $\mathrm{kHz}$ is not enough to detect directly multi-level quadrature-amplitude-modulated signals. If we deal with the coherence lengths as large as several tens of kilometres, the linewidth should be of the order of $1 \mathrm{kHz}$. Well known optical and electrical negative-feedback methods $[5,6]$ can be applied to reduce further the laser linewidth (i.e., the phase noise). These methods reduce the frequency-modulation noise of semiconductor lasers by using a frequency discriminator, which converts a frequency change in the laser output to an intensity change. The output of the discriminator is re-injected to the laser directly (through optical feedback) [5] or is detected by a photodetector to control the laser-injection current (through electrical feedback) [6]. This stabilizes the frequency changes and minimizes the frequency-modulation noise. 
However, the above systems are very bulky and vulnerable to environmental conditions, since a bulky Fabry-Perot interferometer is usually used as a frequency discriminator. Moreover, it can turn out to be not good enough to remove the phase noise at the remote receiver which is distant more than the laser coherence length and/or where a slow phase noise is added during data transmission, e.g. due to slow optical-path length changes associated with environmental perturbations.

As a consequence, many research groups have investigated the techniques for phase-error compensation in the coherent optical-data transmission systems, in order to remove or overcome the phase noise by adopting digital signal-processing (DSP) techniques [7-10]. The speed of DSP circuits is now getting higher and higher, thus enabling one to implement quasi-real-time compensation of the phase error in a coherent receiver. However, coherent receivers based on the DSP still require complex and expensive electronics. Even if we use a complex DSP algorithm, severe phase errors can remain non-compensated. To reduce the burden of DSP present in a coherent receiver, optical phase-locked loops or Costas loops has been widely applied, which use homodyne optical phase-locked loops [11-13]. Nevertheless, a coherent detection at higher symbol rates still requires an off-line DSP $[9,10]$. Even though fast enough DSP algorithms are likely to become real-time, still their latency may not be acceptable for practical real-time data-transmission systems.

To overcome the above problems, recently we have suggested a new method that tracks and compensates externally the phase error in the receiver [14, 15]. These phase-error detection and compensation make it possible to realize a real-time detection of quadrature-phase shift-keying (QPSK) data, which would have not been possible in the conventional frequency-error detection and compensation techniques. To extract the phase-error information, we perform phase modulation and detect in-phase and quadrature-phase $(I / Q)$ signals by a homodyne mixing. The phase-error compensation is achieved directly, i.e. by simply applying an error signal to an external phase modulator, where the error signal is generated to keep the same power level for the detected $\mathrm{I} / \mathrm{Q}$ signals.

In our previous reports $[16,17]$, we have demonstrated a coherent data transmission over the distances reaching the coherent length of a laser source in the order of magnitude, thus limiting the transmission length to less than $10 \mathrm{~km}$. In this work, we describe the idea of our phase-error tracking and compensation and its improvement, which allow for real-time detection of QPSK data after its transmission over several tens of kilometres, which is notably beyond the typical coherent length of lasers. This means that our idea is applicable for a long-length and high-speed data transmission. As we have already discussed, this direct phase-error compensation technique makes possible a direct detection of QPSK signals with no aid of the DSP. To prove the efficiency of our technique, we transmit the QPSK data at $5 \mathrm{GBd} / \mathrm{s}$ (gigabauds per second) through the optical-fibre lengths up to $25 \mathrm{~km}$. We demonstrate the appropriate eye diagrams and constellations for the signals received. As a possible extension of the idea suggested in the present work, we demonstrate a direct detection of $5 \mathrm{GBd} / \mathrm{s}$ QPSK data, using a three-channel WDM technique.

\section{Principles of phase-error tracking and compensation}

Conventional optical phase-locked loops compensate the phase error by adjusting the oscillating frequency of a local-oscillator (LO) laser [11-13]. The phase error is converted into feedback current to control the injection current of LO laser, which induces a laser-frequency shift. These optical phase-locked loops can manifest relatively large tracking bandwidth, though the relevant accuracy may not be good enough to detect directly a coherently modulated signal without the aid of DSP.

Here we use the phase-error signal to compensate directly the LO phase, using an external phase modulator. We adopt and improve further the compensation idea [14] and apply it to 
compensate the phase error in the LO. Fig. 1 illustrates how we extract the phase error between the data and the LO signal. First let us ignore the components inside the dot-lined boxes. The output of a laser source is divided into two arms by a $3 \mathrm{~dB}$ coupler for forming the data and the LO signals. The light in the upper arm passes a 45-deg delay line and a phase modulator for sinusoidal modulation, thus forming a modulated-data signal $P_{s}$. The light in the lower arm passes another phase modulator for compensating the phase error, thus forming the LO signal $\left(P_{L O}\right)$.

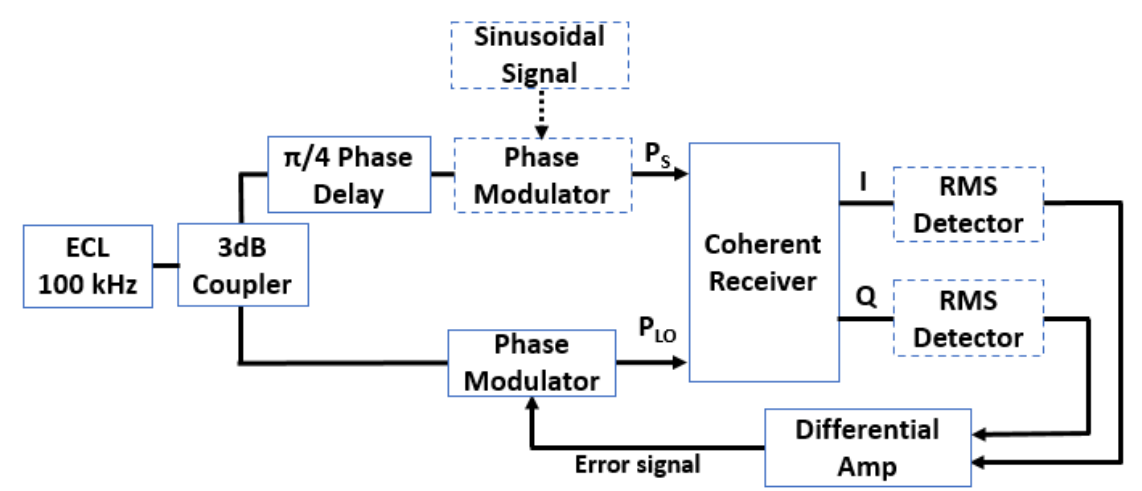

Fig. 1. Schematic diagram showing a principle of our phase-error detection based on coherent detection: 'ECL', 'RMS' and 'Amp' denote respectively 'external-cavity laser', 'root-mean-square' and 'amplifier'.

To simplify the problem, let us assume an ideal case of no phase error and/or no fluctuations. Since the data and the LO signals have the phase difference $45 \mathrm{deg}$, in-phase $(I)$ and quadrature-phase $(Q)$ outputs at a coherent receiver have exactly the same level. If there appears any phase delay (i.e., error) added to the data due to environmental perturbations, the $Q$ output increases, whereas the $I$ output decreases. If we take the difference between the $I$ and $Q$ outputs and feedback this difference to a phase modulator to compensate the phase delay at the LO, we can compensate the phase error induced by the laser source itself and by any other possible phase perturbations. In a practical high-speed receiver, we apply a sinusoidal phase jitter to the phase-modulator signal to remove a possible low-frequency noise. This jitter is also efficient in removing electrical noises in the feedback loop. The working principle is exactly the same as in the case of no phase jitter, although we need to simply add a root-mean-square power detector at the $I$ and $Q$ outputs to take the average powers of sinusoidal outputs.

Fig. 2 shows a schematic diagram of sinusoidal phase perturbation and preliminary experimental results obtained for the phase-error compensation. Without the phase-error compensation, coherently detected $I$ and $Q$ signals show very noisy and similar traces at the

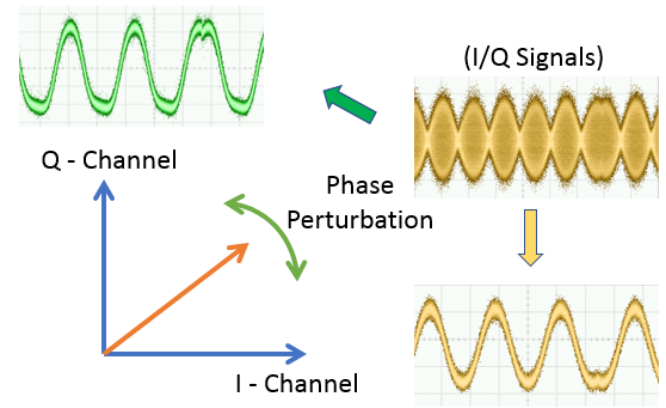

Fig. 2. Schematic diagram of a sinusoidal phase perturbation, and preliminary experimental results obtained for the phase-error compensation. 
sinusoidal phase modulation, as shown in the top right panel of Fig. 2. This is mainly due to a laser phase noise. When we compensate the phase error (see Fig. 1), the $I$ and $Q$ outputs show clear phase-modulated sinusoidal signals, as indicated by green (for the $Q$ signal - see the top left panel) and yellow (for the $I$ signal - see the right bottom panel of Fig. 2) traces. Note that the $I$ and $Q$ signals are out of phase, as explained above.

\section{Experimental setup}

Fig. 3 shows a scheme of our experiment setup for generating and detecting optical QPSK data. As a transmitter laser, a continuous-wave external-cavity laser (Thorlabs SFL 1550P) operating at $1550 \mathrm{~nm}$ (the linewidth $100 \mathrm{kHz}$ ) is used. The output of the external-cavity laser is divided into LO (lower arm) and data (upper arm) signals by a $3 \mathrm{~dB}$ coupler. The LO signal $\left(P_{L O}\right)$ is phase-error compensated by a phase modulator located in front of the receiver. The LO power is kept at $5 \mathrm{dBm}$. The data signal $P_{S}$ is quadrature-phase-modulated by an optical $I / Q$ modulator (Sumicem $\# 32-16110$ ) at $5 \mathrm{GBd} / \mathrm{s}$. The $I / Q$ modulator is driven by a pulse pattern generator with the pattern of pseudo-random binary sequence of the length $2^{31}-1$. The $I$ and $Q$ channels of the QPSK are implemented by applying respectively the data output and the one-bit delayed data-bar output to the $I / Q$ modulator. An intensity modulator is inserted only to form WDM channels. It is not necessary in the case of single-channel transmission.

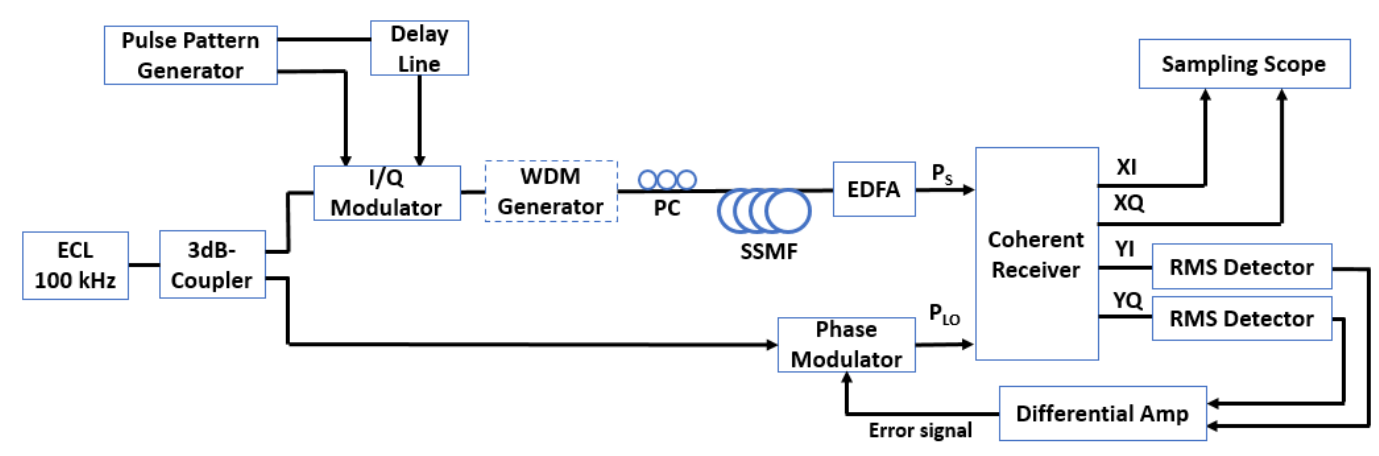

Fig. 3. Schematic diagram of our experiment setup for generating and detecting QPSK data. Abbreviations are as follows: ECL - external-cavity laser, RMS detector - root-mean-square detector, EDFA - erbium-doped fibre amplifier, and Amp - amplifier.

A polarization controller is used to feed the light polarized at 45 deg to the coherent receiver, in order to ensure the same power levels for the orthogonally polarized $X$ and $Y$ signals. The data signals are then transmitted through a standard single-mode fibre (SSMF) G652D. No in-line optical dispersion-compensating fibre is used to compensate the chromatic dispersion. An erbium-doped fibre amplifier is used to keep the constant power level $(0 \mathrm{dBm})$ for both transmitted and back-to-back signals at the receiver. The $I$ and $Q$ channels $X I$ and $X Q$ of the $X$-polarized signal are recorded by a fast digital oscilloscope (Agilent 86100A). The other outputs, $Y I$ and $Y Q$, of the $Y$-polarized signal are power-detected and fed to the positive and negative inputs of a differential amplifier (New Focus LB1005) in order to obtain the difference between the powers of $Y I$ and $Y Q$ signals.

As explained in Section 2, the balance between the $Y I$ and $Y Q$ signal powers ensures the phase offset of 45 deg between the data carrier and the LO. Note that this phase offset (i.e., the power balance between the $Y I$ and $Y Q$ channels) is valid for the randomly modulated QPSK data. A

Ukr. J. Phys. Opt. 2021, Volume 22 
nonzero value of the output of differential amplifier testifies a phase error between the data carrier and the LO signal, which is induced by various phase-noise sources. Therefore, the output of differential amplifier (i.e., the error signal) is applied to the phase modulator to adjust the phase of the LO signal. This yields in efficient phase-error compensation for the QPSK data. The differential amplifier with the optimal integration time and bandwidth provides a stable feedback control.

Hence, the feedback loop works in a simple and efficient way. It compensates any phase error induced by the laser source and the external turbulence (such as temperature, vibration, etc.) during the QPSK-data transmission. In the case of multi-channel WDM transmission, we utilize a WDM generator located after the $I / Q$ modulator. We do not use any channel filter at the receiver to select a target channel. Instead, we mix all the channels into the LO signal, which is synchronized and phase-locked to one of the WDM carriers. A band-limited receiver removes any inter-channel interference noise.

\section{Experimental results and discussion}

To illustrate the performance of our technique step by step, we first check the eye diagrams of the $I$ and $Q$ outputs and compare the constellations for the cases when the technique is applied or not. We consider back-to-back, $10 \mathrm{~km}$ and $25 \mathrm{~km}$ transmissions through the SSMF. The eye-diagram and the constellation traces are obtained directly from a sampling scope at persistent traces for about $1 \mathrm{~min}$. Therefore, the eye diagrams for the both $I$ and $Q$ outputs are simple time traces, and the corresponding QPSK constellation is obtained by feeding the $X I$ and $X Q$ outputs to the horizontal and vertical inputs of the sampling scope. This causes weak traces between the constellation symbol points sampled at the symbol transition.

\section{1. $5 \mathrm{GBd} / \mathrm{s}$ QPSK-data transmission over up to 25-km distances in SSMF}

First of all, we try to find out how far we can send the $5 \mathrm{GBd} / \mathrm{s}$ QPSK data through the SSMF. As mentioned above, the WDM generator inside the dotted box in Fig. 3 is not used in the case of single-channel transmission. Since the phase error-compensation based on the coherent detection reduces effectively the laser linewidth, it is possible to detect directly the QPSK data $[14,15]$. We expect that the linewidth is reduced to $\sim 10 \mathrm{kHz}$, i.e. the coherent length is equal to $5 \mathrm{~km}$ in the free space. In the previous work [14] we have shown that the data-transmission length can be of the order of laser coherent length. Here we examine what happens when the transmission length is evidently larger than the coherent length. It is also important because the transmission length reported in the previous work has been too short to cover the practical case of local-area network applications. Here we choose the fibre length to be $25 \mathrm{~km}$, which is large enough for applying in local area networks and surely essentially longer than the typical coherent length of lasers.

In Fig. 4, we display the eye diagrams for the $I$ and $Q$ outputs after $25 \mathrm{~km}$ transmission, as obtained under condition of no phase-error compensation (Fig. 4a) and when our phase-error compensation scheme is applied (Fig. 4b). In the first case, the eye diagrams are almost closed. On the contrary, wide and clear eye openings can be seen in the second case. Due to random nature of the data, the eye-diagram traces for the both $I$ and $Q$ outputs are very similar. Fig. 5 displays the corresponding constellations for the QPSK data. When no phase-error compensation is applied, the constellation rotates randomly the symbol points of the QPSK data, thus proving that it is impossible to detect the correct QPSK data. After applying the phase-error compensation, one can observe stable symbol positions for the QPSK data, as expected from the eye diagrams shown in Fig. 4b. In this manner, the phase-noise effect has been reduced using no DSP algorithm. The potential of our method is again confirmed by the constellation. 
I channel

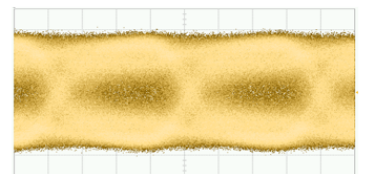

(a)

I channel

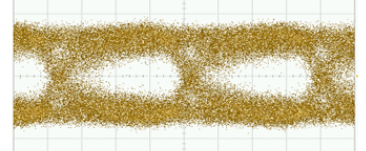

(b)

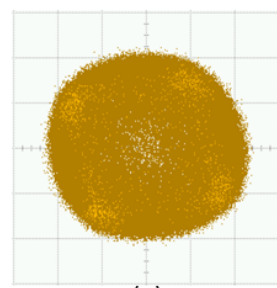

(a)
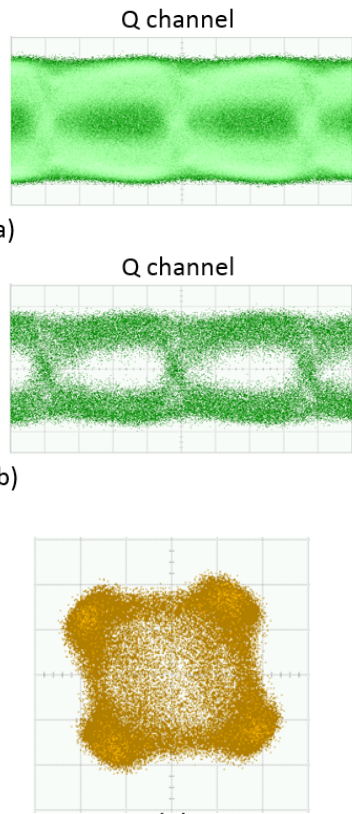

(b)
Fig. 4. Eye diagrams for $I$ and $Q$ outputs after $25 \mathrm{~km}$ transmission of the $5 \mathrm{GBd} / \mathrm{s}$ QPSK data; (a) without phase-error compensation, and (b) with phase-error compensation.

To examine the changes occurring in the constellation with changing transmission distance in the SSMF, we show in Fig. 6 the constellations that correspond to the cases of back-to-back, 10-km and $25-\mathrm{km}$ transmissions. It seems that the laser coherence length does not affect the distance of successful transmission critically. Of course, the phase fluctuations during data transmission and the noise associated with amplified spontaneous emission in erbium-doped fibre amplifier, which is used to compensate the SSMF losses, enhance the random phase noise in the data received. However, although the performance degrades notably in the case of $25-\mathrm{km}$ transmission in the SSMF, it remains high enough to detect directly the transmitted data.

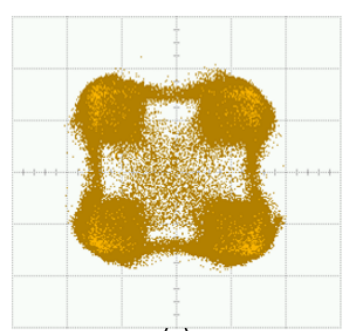

(a)

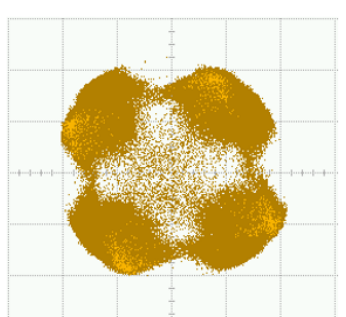

(b)

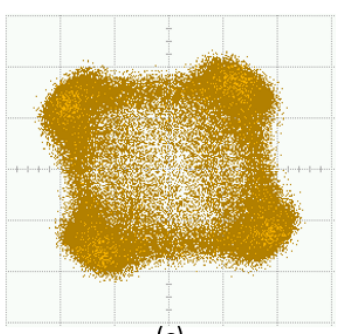

(c)

Fig. 6. Constellations for $5 \mathrm{GBd} / \mathrm{s}$ QPSK data transmitted according to back-to-back scheme (a) and over the distances $10 \mathrm{~km}(\mathrm{~b})$ and $25 \mathrm{~km}(\mathrm{c})$.

\subsection{Possible extension of our technique to WDM data transmission}

Now we try to confirm that our technique can be successfully applied to the case of WDM-based transmission systems. To implement the WDM channels, we employ the WDM generator (shown in Fig. 3 as a dotted box). It is well known that an optical-frequency comb technique is readily available for the WDM-channel carriers [16-18]. The optical-frequency comb can be implemented by applying pulse carving with intensity modulators and a linear chirp through phase modulators [16]. Since the inter-channel interference remains significant for the nearest channels, we consider only three WDM channels, a target one and two neighbouring channels.

Ukr. J. Phys. Opt. 2021, Volume 22 
A relatively small number of spectral-comb lines can be implemented simply by using a single intensity modulator. Driving the intensity modulator at appropriate DC bias and modulation depth, one can generate spectral-comb lines and so form three different WDM channels. Fig. 7 shows a scheme of a simple WDM generator and a process of generation of three WDM carriers with the $10 \mathrm{GHz}$ spacing. At the receiver end, we demodulate one of the three WDM channels, the central one, since this channel experiences the most severe inter-channel interference. To select the central channel, we carry on a well-known homodyne detection and remove the beating noise between the neighbouring channels, using a limited bandwidth of the receiver [18].

Fig. 8 shows the eye diagrams for the $I$ (yellow traces) and $Q$ (green traces) outputs, as well as the corresponding constellations for the demodulated $5 \mathrm{GBd} / \mathrm{s}$ QPSK data, as measured for the central channel in the 'back-to-back' regime. For comparison, we show simultaneously the traces obtained when the phase-error compensation is present (Fig. 8b) or absent (Fig. 8a). One can see that the idea suggested in our work works quite well again. If compared with the results shown in Fig. 6a, larger symbol-position errors are observed, which are mainly due to inter-channel interference between the WDM channels. In general, however, the experimental data confirms a great potential of our method and its successful work in the case of direct coherent detection in the multiple WDM system. Unfortunately, it has been difficult to detect correctly the WDM data after 10-km transmission through the SSMF at this moment. This problem will be a subject of our future work.

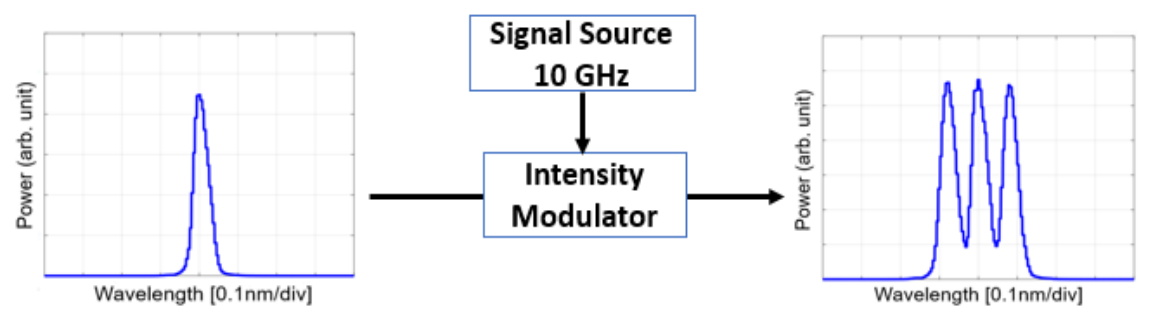

Fig. 7. Scheme of a three-WDM-channel generator based on an intensity modulator. Optical spectra corresponding to the input and the output are shown in left and right panels, respectively.
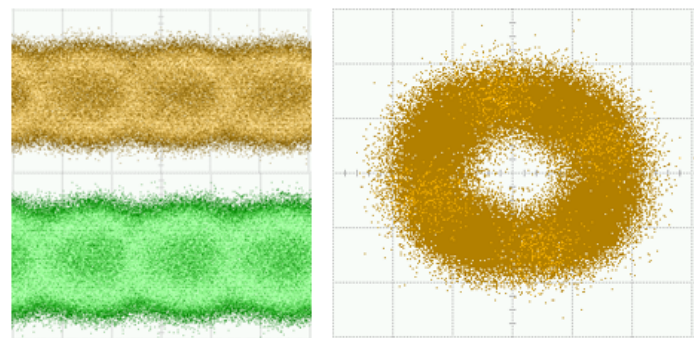

(a)
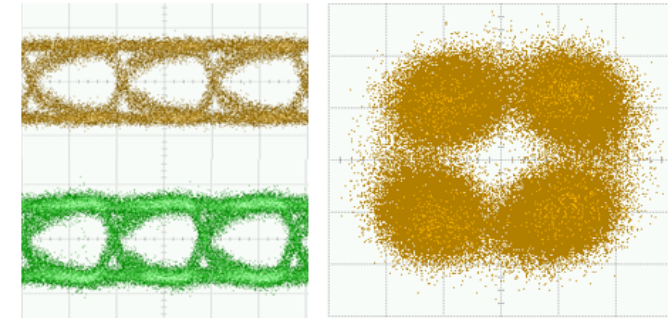

(b)

Fig. 8. Eye diagrams for the I (yellow traces) and $Q$ (green traces) outputs, and the corresponding constellations for demodulated $5 \mathrm{GBd} / \mathrm{s}$ QPSK data in the 'back-to-back' regime, as obtained for the central WDM channel (see also Fig. 7). Both cases, without (a) and with (b) phase-error compensations, are shown for comparison. 


\section{Conclusions}

In the present work, we have suggested a simple new method for overcoming optical phase noises in coherent-detection systems, which does not rely upon the common DSP technique. Its essence is as follows. Initially, we set the phase difference between the data carrier and the LO signal to be equal to $45 \mathrm{deg}$, in order to assure the same power level for the $I$ and $Q$ phase outputs. Then we take the difference between the $I$ and $Q$ outputs and feedback it to compensate a possible phase error of the LO signal. It turns out that this idea works well for relatively long transmission distances, which can be larger than the coherence length of a laser source.

As a proof of the suggested technique, we have achieved a direct coherent detection of the $5 \mathrm{GBd} / \mathrm{s}$ QPSK data transmitted over a $25 \mathrm{~km} \mathrm{SSMF}$ in the real-time mode, using the compensation of phase error. The eye diagrams for the $I$ and $Q$ outputs and the corresponding constellations for the $5 \mathrm{GBd} / \mathrm{s}$ QPSK data reveal a remarkable improvement achieved when utilizing the method proposed in this work. In this way, one can reduce significantly the phase noises from the laser source and the erbium-doped fibre amplifier. Still better improvement is expected after optimizing the performance of feedback loop.

Extending our technique, we have demonstrated a coherent detection of the $5 \mathrm{GBd} / \mathrm{s}$ QPSK data in a WDM system. Even though the inter-symbol interference is enhanced due to multi-channel interference, the results obtained by us testify clearly the great potentials of our method. In principle, it can be readily applied to the other high-level modulation formats such as 8-PSK and 16 QAM at arbitrarily high speeds and transmission distances.

\section{Acknowledgments}

The authors thank Dr. T.T.Tran for helpful discussions. This work was supported by the Basic Science Research Program through the National Research Foundation of Korea (N.R.F.) funded by the Ministry of Education, Science and Technology (\#2016R1D1A1B04930224).

\section{References}

1. Kikuchi K, 2016. Fundamentals of coherent optical fiber communication. J. Lightwave Technol. 34: $157-179$.

2. Leven A, Kaneda N, Koc Ut-Va and Chen Y-K, 2007. Coherent receivers for practical optical communication systems. Conference on Optical Fiber Communication and the National Fiber Optic Engineers Conference, Anaheim, CA, USA, 1-3

3. Ip E, Lau A P T, Barros D J F and Kahn J M, 2008. Coherent detection in optical fiber systems. Opt. Express. 16: 753-791.

4. Colavolpe G, Foggi T, Foretieri E and Secondii M, 2011. Impact of phase noise and compensation techniques in coherent optical systems. J. Lightwave Technol. 29: 2790-2800.

5. Aoyama K, Yoshioka R, Yokota N, Kobayashi W and Yasaka H, 2015. Optical negative feedback for linewidth reduction of semiconductor lasers. IEEE Photon. Technol. Lett. 27: 340-343.

6. Ohtsu $\mathrm{M}$ and Kotajima $\mathrm{S}, 1985$. Linewidth reduction of a semiconductor laser by electrical feedback. IEEE J. Quantum Electron. 21: 1905-1912.

7. Tsukamoto S, Katoh K and Kikuchi K, 2006. Coherent demodulation of optical multilevel phase-shift-keying signals using homodyne detection and digital signal processing. IEEE Photon. Technol. Lett. 18: 1131-1133.

8. Gagnon D-S L Y, Tsukamoto S, Katoh K and Kikuchi K, 2006. Coherent detection of optical quadrature-phase-shift-keying signal with carrier phase estimation. J. Lightwave. Technol. 24: $12-21$.

Ukr. J. Phys. Opt. 2021, Volume 22 
9. Xiang Zhou, Lynn E. Nelson, Peter Magill, Rejoy Isaac, Benyuan Zhu, David W Peckham, Peter I. Borel and Kenneth Carlson, 2013. High spectral efficiency $400 \mathrm{~Gb} / \mathrm{s}$ transmission using PDM time-domain hybrid 32-64 QAM and training-assisted carrier recovery. J. Lightwave. Technol. 31: 999-1005.

10. Li S A, Huang H, Pan Z, Yin R, Wang Y, Fang Y, Zhang Y, Bao C, Ren Y, Li Z and Yue Y, 2020. Enabling technology in high-baud-rate coherent optical communication systems. IEEE Access. 8: 111318-111329.

11. Herzog F, Kudielka K, Eemi D and Bachtold W, 2005. Optical phase locked loop for transparent inter-satellite communications. Opt. Express. 13: 3816-3821.

12. Park H C, Lu M, Bloch E, Reed T, Griffith Z, Johansson L, Coldren L and Rodwell M, 2012. 40Gbit/s coherent optical receiver using a Costas loop. Opt. Express. 20: B197-B203.

13. Liu Y, Tong S, Chang S, Song Y, Dong Y, Zhao X, Ani Z and Yui F, 2018. Design of a phase sensor applied in the optical phase-locked loop based on a high-speed coherent laser communication system. IEEE Access. 6: 22131-22139.

14. Ha T T and Seo D, 2018. Direct demodulation of optical BPSK/QPSK signals without digital signal processing. Radioengineering. 27: 942-947.

15. Ha T T Won Y Y and Seo D, 2019. Spectral width reduction of a laser source by external phase noise compensation. Electron. Lett. 55: 703-704.

16. Tran T T, Song M J. Song M H and Seo D, 2019. Highly flat optical frequency comb generation based on pulse carving and sinusoidal phase modulation. Opt. Eng. 58: 076103.

17. Zhang J, Kim I H, Hong S J and Seo D S, 2011, High speed optical pulse train generation based on line-by-line spectral intensity coding. Ukr. J. Phys. Opt. 12: 117-126.

18. Mazur M, Lorences-Riesgo A, Schroder J, Andrekson P A and Karlsson M, 2018. 10 Tb/s PM-64QAM self-homodyne comb-based superchannel transmission with $4 \%$ shared pilot tone overhead. J. Lightwave Technol. 36: 3176-3184.

Trong-Thuy Ha, Yong-Yuk Won and Dongsun Seo. 2021. 25-km long transmission and real-time detection of 5-GBd/s optical QPSK data using external phase-error compensation. Ukr.J.Phys.Opt. 22: 92 - 100. doi: 10.3116/16091833/22/2/92/2021

Анотація. Запропоновано простий новий метод відстеження та компенсації фазових помилок. Він дає змогу прямо детектувати дані після їхньої оптичної квадратурно-фазової маніпуляиії (КФМ) та передачі на відстані понад $10 \mathrm{kм}$, щзо набагато перевищують когерентну довжину типових лазерних джерел. Фазову помилку визначають, беручи різниию потужностей між сфазованим $i$ квадратурно-фазованим сигналами для випадкових КФМ-даних. Цю помилку компенсують простим поданням сигналу помилки на фазовий модулятор, розташований перед локальним генератором для когерентного детектування. Така пряма компенсація фазової помилки дає змогу детектувати КФМ-дані в режимі реального часу без використання ичифрових технологій обробки сигналів. Як експериментальний доказ дієвості методу, вперие продемонстровано успішну передачу КФМ-даних зі швидкістю 5 Гбод/с крізь стандартне одномодове волокно завдовжки 25 км. Показано також, щзо таку ідею компенсації фазових помилок можна поширити на передачу мультиплексованих КФМ-даних зі спектральним ущчільненням. 